\title{
Determinants of lexical access in speech production: Role of word frequency and age of acquisition
}

\author{
FERNANDO CUETOS, BERNARDO ALVAREZ, and MARÍA GONZÁLEZ-NOSTI \\ Universidad de Oviedo, Oviedo, Spain \\ and \\ ALAIN MÉOT and PATRICK BONIN \\ LAPSCO/CNRS, Université Blaise Pascal, Clermont-Ferrand, France
}

\begin{abstract}
The main determinants of lexical access in speech are considered to be a word's age of acquisition (AoA) and its frequency of occurrence in a speaker's experience. It is unclear whether and how these variables interact, although they are commonly observed to be correlated, for the few studies that address the issue have reported inconsistent findings. An influential view of AoA in lexical processing (Ellis \& Lambon Ralph, 2000) predicts stronger frequency effects for items acquired later in life than for those acquired at an early age. Five experiments were designed to investigate the possible interaction of AoA and frequency effects in speech. We found that the interaction between word frequency and AoA was not robust and that, contrary to expectation, the effect of word frequency was greater for words acquired earlier in life than for those acquired later. The implications of our findings are discussed.
\end{abstract}

The pioneering work of Oldfield and Wingfield (1965) revealed the cardinal importance of word frequency as a determinant of lexical access in speech production. These authors showed that pictures with high-frequency names are processed faster and more accurately than pictures with low-frequency names. Their finding has since been replicated in several other studies (e.g., Humphreys, Riddoch, \& Quinlan, 1988; Huttenlocher \& Kubicek, 1983; Jescheniak \& Levelt, 1994). As a result, speech production models have been formulated to account for the effects of word frequency (see, e.g., Dell, 1990; Levelt, Roelofs, \& Meyer, 1999).

As is often claimed in the literature, earlier studies on word frequency did not take into account other variables that are closely related to word frequency and that may also influence response latencies, such as imageability, conceptual familiarity, age of acquisition (AoA), or length. In effect, these variables are correlated so that more frequent words are also shorter, more concrete, conceptually more familiar, more imageable, and learned earlier in life than those of low frequency (see, e.g., Chalard, Bonin, Méot, Boyer, \& Fayol, 2003; Morrison, Chappell, \& Ellis,

This research was supported by Grants MCT-00-BSO-0315 and MCT03-BSO-00777 from the Spanish government. We thank two anonymous reviewers for helpful comments on an earlier version of this article. Correspondence concerning this article should be addressed to F. Cuetos, Facultad de Psicología, Universidad de Oviedo, Plaza Feijoo, s/n 33003 Oviedo, Spain (e-mail: fcuetos@uniovi.es).

Note-This article was accepted by the previous editorial team, when Colin M. MacLeod was Editor.
1997). Therefore, it remains unclear in these earlier studies whether it was the frequency of the name or any of the other correlated variables that accounted for variations in naming latencies. In particular, it has become established that the AoA of words needs to be taken into account in investigations of the influence of word frequency (see, e.g., Chalard et al., 2003). In a pioneering multiple regression study, Carroll and White (1973) investigated the determinants of naming latencies. Participants had to name 103 pictures, and naming times were recorded and analyzed. Among the predictors of naming times were AoA, word frequency, and length. The results showed that AoA was the only reliable predictor. Since then, other picture naming studies have adopted a multiple regression approach and have also reported that AoA has a reliable influence over naming times but the objective variable of word frequency does not (Bonin, Chalard, Méot, \& Fayol, 2002; Gilhooly \& Gilhooly, 1979; Morrison, Ellis, \& Quinlan, 1992; Vitkovitch \& Tyrell, 1995). However, other multiple regression studies have found reliable effects of both variables (Barry, Morrison, \& Ellis, 1997; Cuetos, Ellis, \& Alvarez, 1999; Ellis \& Morrison, 1998; Lachman, Shaffer, \& Hennrikus, 1974; Snodgrass \& Yuditsky, 1996). Bonin, Fayol, and Chalard (2001) and Barry, Hirsh, Johnston, and Williams (2001) varied AoA and controlled for word frequency in some experiments and did the opposite in others. They found a reliable effect for AoA but not for word frequency. However, it is now established that both AoA and word frequency have reliable effects on naming times (Ellis \& Lambon Ralph, 2000). This is true even though AoA seems to be more robust than word frequency, since the latter has sometimes been found not to be reliable 
whereas the former has always been found to be reliable when both variables were taken into account (Alario et al., 2004; Johnston \& Barry, in press). A crucial issue is the need to account for the effects of both variables in spoken production models.

Object naming can be modeled as involving four main processing levels: object identification, semantic access, lexical activation, and articulation. In Levelt et al.'s (1999) theory of spoken production, the effect of word frequency is located at the lexical level and, more precisely, at the level of the phonological forms of the words (the lexeme level). Levelt et al. implicitly admitted that word frequency and AoA were interchangeable. Therefore, the explanation put forward to account for word frequency effects in speech production could be transposed to account for AoA effects. However, AoA and word frequency are two distinct, important factors that need to be accounted for (Bonin, Barry, Méot, \& Chalard, 2004). A serious limitation of the Levelt et al. theory is therefore that it does not explicitly take into account the influence of AoA in naming speed in addition to that of word frequency. As Lambon Ralph and Ehsan (2006) claim, until recently there were very few explanations for AoA effects. It is not our intention to review all of them (see Johnston \& Barry, in press, for a review). For our purposes, the most influential view is that put forward by Ellis and Lambon Ralph (2000).

In the connectionist simulations of lexical processing reported by Ellis and Lambon Ralph (2000), AoA effects emerge as a result of a loss of plasticity in the network during learning. Patterns that are introduced early in network training benefit from the fact that the system is at its most plastic at the beginning of learning, whereas patterns that are introduced later can still be learned, but not as effectively as early patterns (they must struggle to be represented). From this point of view, AoA and word frequency share a common locus: the links relating different kinds of representations (see also Zevin \& Seidenberg, 2002). The simulations performed by Ellis and Lambon Ralph showed that word frequency also has an influence on network performance, with the result that the patterns that are frequently presented to the network achieve better representation than those introduced less frequently (see their Simulation 11). Moreover, word frequency and AoA interact so that a larger influence of word frequency is observed on patterns introduced late than on those introduced early. Therefore, Ellis and Lambon Ralph's view predicts an interaction between word frequency and AoA in behavioral data. However, the few studies in which this interaction has been investigated in spoken word production have yielded inconsistent findings (see below). In effect, as claimed by Lambon Ralph and Ehsan (2006), there is a surprising paucity of data on the issue of whether or not AoA and word frequency interact. The investigation of this interaction is important both empirically and theoretically. From an empirical point of view, given the lack of consistent findings among the few studies that have addressed this issue, there is a great need to test the possible interaction in a systematic manner. In the present study, we sought converging evidence using both a factorial approach and a regression approach. From a theoretical point of view, the finding of an interaction between word frequency and AoA would provide additional support for Ellis and Lambon Ralph's connectionist view of AoA and word frequency in lexical processing. Lambon Ralph and Ehsan used the same network as did Ellis and Lambon Ralph to explore the influence of AoA and frequency as a function of types of mapping between input and output patterns. Their most important finding was that a word frequency $\times$ AoA interaction affected network performance for arbitrary mappings (which corresponds to the situation of picture naming). The interaction resulted in a larger frequency effect for patterns acquired later in life.

In the present study, we tested the interaction between word frequency and AoA in picture naming latencies in normal participants using both a factorial approach and a regression approach. The examination of the interaction between word frequency and AoA is somewhat complicated by the nature of the AoA variable. Whereas word frequency is an objective measure, word AoA is generally obtained by asking adults to rate, on a point scale, the age at which they think they learned each word presented in a list. However, this procedure has been criticized because adults cannot remember the exact age at which they learned different words. Such ratings are further influenced by other factors, such as the familiarity of the concept evoked by the word and the frequency with which the word is encountered (Chalard et al., 2003). Other methods for estimating the AoA of words are to consult children's books or analyze the vocabulary of children of different ages. The measures obtained by both methods are strongly correlated. Carroll and White (1973) found a correlation of .85 between the subjective scales and the use of words in children's books. Gilhooly and Gilhooly (1980) found a correlation of .84 between the subjective scales and definitions given by children of different ages (see also Morrison et al., 1997; Pind, Jónsdóttir, Gissurardóttir, \& Jónsson, 2000).

In an influential study, Zevin and Seidenberg (2002) raised important issues related to both word frequency and AoA measures. With respect to word frequency, they argued that frequency norms derived from adult texts are generally used in AoA studies but do not reliably reflect the number of times words are encountered over the life span. There is an important phase of exposure to words during childhood that is not taken into account in adult frequency counts. Therefore, Zevin and Seidenberg (2002) advocate the use of cumulative frequency norms, which correspond to the frequency of use of a word throughout childhood (considering reading books and textbooks for children at different age levels) plus the frequency of its use in adult texts. Zevin and Seidenberg (2002) also raised concerns about the use of objective AoA norms to predict lexical processing because of its status as a performance variable. According to them, it is not surprising that children's performance in picture naming (from which "objective" AoA measures are derived) predicts the performance of adults 
in the same task, since both are dependent variables that result from other factors. To avoid this problem, Zevin and Seidenberg (2002) introduced the concept of frequency trajectory, which refers to the variation of frequencies over the life span. Words that are more frequently encountered during an initial period of acquisition are those that are learned first (see Bonin et al., 2004, and Zevin \& Seidenberg, 2004, for converging evidence). According to Zevin and Seidenberg (2002), frequency trajectory measures, and not classical AoA measures obtained from adult ratings or from child performance, should be used to study age-limited learning effects. Recently, Bonin et al. (2004) investigated frequency trajectory and cumulative frequency effects in various lexical processing tasks (spoken/written naming, word reading, spelling to dictation, and lexical decision). Interestingly, they reanalyzed a picture naming experiment that they had conducted 2 years earlier (Bonin et al., 2002) and found reliable effects of both cumulative frequency and frequency trajectory in picture naming latencies.

The close relationship between rated/objective AoA norms and word frequency measures means that it is difficult to find high-frequency stimuli that are acquired late in life and low-frequency stimuli that are acquired early. Perhaps for this reason, few picture naming experiments using a factorial design have been conducted to date. A recent study in which the variables of AoA and frequency were crossed factorially is that of Meschyan and Hernandez (2002). In their first experiment, the authors varied orthogonally AoA and word frequency as well as the delay ( 0 vs. 2,200 $\mathrm{msec}$ ) between the picture onset and a naming cue. They used subjective word frequency measures and objective AoA scores taken from the Morrison et al. (1997) study. Meschyan and Hernandez found significant effects of AoA, no reliable effects of word frequency, and no reliable interaction between the two variables in immediate naming (i.e., interval 0 ). In their second experiment, in which two new delays (750 and 1,500 msec) were added, they found effects of both AoA and word frequency at the 0 interval but no reliable interaction between the two factors. However, in another recent study (Lambon Ralph \& Ehsan, 2006), an interaction between word frequency and AoA was found to affect both picture naming and word reading latencies.

The interaction between word frequency and AoA was tested by Barry et al. (1997) in a multiple regression analysis. They found a reliable interaction, with the result that a larger frequency effect was found on items acquired late than on those acquired early. It must be stressed, however, that this interaction was not obtained with the use of objective AoA norms, which suggests that the interaction may not be robust. Chalard et al. (2003), using different measures of word frequency, also did not find a reliable interaction between the two factors in picture naming in French.

The lack of a reliable interaction between AoA and word frequency found in certain studies (e.g., Chalard et al., 2003; Meschyan \& Hernandez, 2002) is at odds with the Ellis and Lambon Ralph (2000) connectionist model, which clearly predicts an interaction between the two variables (see also Lambon Ralph \& Ehsan, 2006). It also contrasts with reports of a reliable interaction on naming latencies found by Barry et al. (1997) and Lambon Ralph and Ehsan. However, as far as the Lambon Ralph and Ehsan study is concerned, it is worth mentioning that the interaction between word frequency and AoA was not reliable for items.

Given (1) the lack of consistent findings on the interaction between AoA and word frequency in the few picture naming studies in which it was tested and (2) the implication it may have on the modeling of AoA and word frequency effects in spoken word production, we decided to investigate this interaction in picture naming latencies in a more systematic manner by using both a factorial approach and a regression approach. We report four experiments in which a factorial design was used. In the first three, adult frequency measures were used, and cumulative frequency was used in the fourth. Adult ratings of AoA were used in Experiments 1, 2, and 4, whereas objective AoA measures were used in Experiment 3. In a fifth experiment, we used the regression approach, including all the measures of frequency and AoA. We sought to determine whether or not the critical interaction is found independently of the AoA measure used (subjective or objective). The aim of these experiments was to test whether or not the frequency effect would be reliably larger for words acquired late than for those acquired early, as predicted by Ellis and Lambon Ralph's (2000) model.

\section{EXPERIMENT 1}

\section{Method}

Participants. Thirty-two psychology students at the University of Oviedo participated in the experiment. All had normal or correctedto-normal vision and were native speakers of Spanish.

Stimuli. Sixty pictures were used, 15 in each of the following four experimental conditions: early AoA-high frequency, early AoA-low frequency, late AoA-high frequency, and late AoA-low frequency. The pictures were selected from a database of 800 pictures taken from Snodgrass and Vanderwart (1980); Bonin, Peereman, Malardier, Méot, and Chalard (2003); and Cycowicz, Friedman, Rothstein, and Snodgrass (1997), plus some from tests such as the Peabody test (Dunn \& Dunn, 1986) and EPLA (Valle \& Cuetos, 1995).

Familiarity ratings were obtained from a sample of 28 students at the University of Oviedo, who were asked to judge the degree to which they came in contact with or thought about the object represented by a word. A 7-point scale was used on which 1 indicated very unfamiliar and 7 very familiar. Imageability ratings were obtained from an additional 28 students at the University of Oviedo, who were asked to indicate, on a scale on which 1 indicated very easy and 7 indicated very difficult, the degree of difficulty in eliciting the image of the object represented by the word. Visual complexity ratings were obtained from another pool of 28 students, who had to rate the complexity of each drawing on a 5-point scale on which 1 indicated drawing very simple and 5 indicated drawing very complex. Similarly, AoA ratings were obtained following the procedure of Gilhooly and Logie (1980): Twenty-eight additional students were asked to estimate the age at which they had learned each word. Each point on the scale represented 2 years in the participant's life: 1 indicated that the participant thought he or she had learned the word by the age of 2 years; 2 , that he or she had learned it at 3-4 years of age, and so on; finally, 7 indicated that the participant estimated that he 
or she had learned the word after 13 years of age. Word frequencies were taken from the LEXESP database (Sebastián, Martí, Carreiras, $\&$ Cuetos, 2000), on a corpus of 5 million words that included a representative sample of written texts (novels, newspapers, essays, etc.). All the pictures had name agreement above $85 \%$. The means for the statistical characteristics of the items are presented in Table 1. There were no reliable differences among the four conditions with respect to the variables of familiarity, imageability, visual complexity, and length. As for the initial phoneme, the four experimental conditions had roughly the same number of words starting with voiced and with voiceless phonemes (only the third condition had more words starting with voiced than with voiceless phonemes). A list of the items is provided in Appendix A.

Procedure. The experiment was run in the psychology laboratory of the University of Oviedo. The participants entered a soundproof room 1 at a time. A microphone was placed in front of the participant's mouth and connected to a voice key that collected his or her responses. The experiment was run with the Superlab program (Beringer, 1995), and the task was to name black-and-white images that appeared on a computer screen. Naming latencies were recorded by the voice key. All of the stimuli were randomized for each participant, with the restriction that no more than three stimuli of the same category ever appeared consecutively. Prior to the experiment, each participant was given the complete list of pictures for naming and received feedback on the names. The reason for this previous presentation was to bring the procedure in line with the standard pattern in psycholinguistics, since most picture naming experiments include this process of familiarizing participants with the stimuli. Once this previous stage was completed and after a short rest, the experiment began and the participant was no longer corrected. Latencies and errors were then recorded.

\section{Results}

Prior to the statistical analysis, all errors committed by the participants in picture naming $(2.29 \%$ of responses), voice key failures $(0.78 \%$ of responses $)$, and values more than $2.5 S D$ s from the mean (3.54\% of responses) were eliminated. All effects reported here as significant are at an alpha level of at least .05.

In Table 2, the mean naming latencies (in milliseconds), their $S D$ s, and percentages of errors are provided.

The main effect of AoA was significant across both participants $\left[F_{1}(1,31)=13.40\right]$ and stimuli $\left[F_{2}(1,56)=\right.$ $6.40]$. Word frequency was significant neither for participants $\left[F_{1}(1,31)=1.05\right]$ nor for stimuli $\left(F_{2}<1\right)$. The interaction was significant neither for participants $\left[F_{1}(1,31)=\right.$ 2.95] nor for stimuli $\left(F_{2}<1\right)$.

Table 1

Statistical Characteristics of the Items Used in Experiment 1

\begin{tabular}{lrrrrr}
\hline & \multicolumn{2}{c}{ Early Acquired } & & \multicolumn{2}{c}{ Late Acquired } \\
\cline { 2 - 3 } \multicolumn{1}{c}{ Characteristic } & HF & LF & & HF & LF \\
\hline AoA (rated) & 1.54 & 1.83 & & 3.64 & 3.78 \\
Frequency (per million) & 32.75 & 3.76 & & 25.26 & 3.78 \\
Visual complexity & 2.65 & 2.34 & & 2.40 & 2.92 \\
Imageability & 6.30 & 6.27 & & 5.79 & 6.11 \\
Familiarity & 6.23 & 5.89 & & 5.38 & 4.56 \\
No. of syllables & 2.47 & 2.53 & & 2.53 & 2.73 \\
No. of phonemes & 5.13 & 5.47 & 5.60 & 6.00 \\
\hline
\end{tabular}

Note-HF, high frequency; LF, low frequency. Visual complexity was rated on a scale of $1-5$, and imageability and familiarity on scales of $1-7$.
Table 2

Mean Naming Times (RTs, in Milliseconds), Their Standard Deviations, and Percentages of Errors As a Function of AoA and Word Frequency in Experiment 1

\begin{tabular}{cccc}
\hline Word & RT & $S D$ & \%Error \\
\hline Early acquired & & & \\
High frequency & 682 & 102 & 0.47 \\
Low frequency & 661 & & 0.73 \\
Late acquired & & 101 & \\
High frequency & 714 & 111 & 0.47 \\
Low frequency & 712 & & 0.62 \\
\hline
\end{tabular}

\section{Discussion}

In this experiment, in which a factorial design was used, the results were similar to previous findings reported in the literature: AoA had a significant effect on naming times, and word frequency failed to reach significance (see, e.g., Barry et al., 2001; Bonin et al., 2001). Furthermore, there was no reliable interaction between the two factors.

\section{EXPERIMENT 2}

Experiment 2 was similar to Experiment 1 except that it was conducted in French.

\section{Method}

Participants. Thirty psychology students at the University of Clermont-Ferrand participated in the experiment. All had normal or corrected-to-normal vision and were native speakers of French.

Stimuli. Sixty-eight pictures were used, 17 in each of the following four experimental conditions: early AoA-high frequency, early AoA-low frequency, late AoA-high frequency, and late AoA-low frequency. The pictures were selected from the Cycowicz et al. (1997) study.

Conceptual familiarity, imageability/image variability, visual complexity, name agreement, and AoA ratings were obtained from Alario and Ferrand's (1999) norming study. Word frequency estimations were taken from the Brulex database (Content, Mousty, \& Radeau, 1990) and from the Lexique database (New, Pallier, Ferrand, \& Matos, 2001). Brulex frequencies are based on a smaller corpus than the LEXIQUE database, the latter of which is a corpus of 31 million words covering all parts of speech of the French language. Lexique is the current reference tool for psycholinguists in French. Phonological and syllable length were not perfectly matched across high- and low-frequency items. Therefore, these were introduced as covariate factors in the items analysis.

The means for the statistical characteristics of the items are presented in Table 3, and the list of the items is provided in Appendix B.

Procedure. The procedure used was the same as in Experiment 1 except that naming latencies were recorded with an Apple Macintosh and PsyScope software (Cohen, MacWhinney, Flatt, \& Provost, 1993) was used. Also, the learning phase was less stringent than that in Experiment 1 , since no feedback on the picture names was provided.

\section{Results}

The procedure used to eliminate the data in Experiment 1 was applied here: Voice key failures (2.9\%), participant errors $(4.17 \%)$, and values more than 2 SDs from the mean $(2.25 \%)$ were eliminated from the analyses. Mean naming latencies, their $S D$ s, and error rates are provided in Table 4. 
Table 3

Statistical Characteristics of the Items Used in Experiment 2

\begin{tabular}{lccccc}
\hline & \multicolumn{2}{c}{ Early Acquired } & & \multicolumn{2}{c}{ Late Acquired } \\
\cline { 2 - 3 } \cline { 5 - 6 } \multicolumn{1}{c}{ Characteristic } & HF & LF & & HF & LF \\
\hline AoA (rated) & 1.91 & 1.95 & & 2.82 & 2.95 \\
Frequency (Brulex) & 1.49 & 0.68 & & 1.47 & 0.54 \\
Frequency (LEXIQUE) & 2.20 & 1.80 & 2.49 & 1.79 \\
Visual complexity & 2.95 & 2.93 & 2.94 & 2.95 \\
Imageability & 2.86 & 2.99 & 2.77 & 2.82 \\
Familiarity & 2.90 & 3.20 & 2.85 & 2.61 \\
No. of syllables & 1.41 & 2.00 & 1.71 & 2.00 \\
No. of phonemes & 3.71 & 4.76 & 4.35 & 5.12 \\
\hline
\end{tabular}

Note-HF, high frequency; LF, low frequency. Visual complexity was rated on a scale of 1-5, and imageability and familiarity on scales of 1-7 (Alario \& Farrand, 1999).

The main effect of AoA was significant for both participants $\left[F_{1}(1,29)=60.87\right]$ and items $\left[F_{2}(1,62)=7.19\right]$. Word frequency was significant for participants $\left[F_{1}(1,29)=\right.$ 6.61] but not for items $\left(F_{2}<1\right)$. The interaction was significant for participants $\left[F_{1}(1,29)=14.70\right]$ but failed to reach significance for items $\left[F_{2}(1,62)=3.15\right]$. The interaction indicated that the frequency effect was larger and reversed on items acquired early $(+68 \mathrm{msec})$ than on those acquired late $(-17 \mathrm{msec})$.

\section{Discussion}

This experiment was very similar to that conducted in Spanish except that the learning of the pictures before the naming experiment was less stringent. As in Experiment 1, a reliable effect of AoA was found, whereas word frequency was reliable only in the participants analysis. Importantly, the interaction was significant in the participants analysis but failed to reach significance in the items analysis. Moreover, the form of the interaction was not in accord with that predicted by Ellis and Lambon Ralph (2000) and Lambon Ralph and Ehsan (2006), since the influence of word frequency was stronger on items acquired early than on those acquired late and, moreover, the frequency effect was reversed on items acquired early. In Experiments 3 and 4 , which were conducted only in Spanish, a factorial design was again used. In Experiment 3, objective AoA measures were used. This type of measure has become common in AoA studies and has been claimed to be preferable to AoA ratings (Morrison \& Ellis, 2000; but see Zevin \& Seidenberg, 2002). In Experiment 4, rated AoA measures and a cumulative frequency measure were used.

\section{EXPERIMENT 3}

We began this experiment by collecting objective data on AoA for Spanish words. Following the procedure used by Morrison et al. (1997), we obtained naming data from children of different ages. On individual cards, 345 pictures of objects from the same databases used in Experiment 1 were presented to children $26-187$ months of age (i.e., $2-15.5$ years of age) for naming. We established 6-month intervals in the period comprised from the 26th to the 97th month and 12-month intervals in the period from the 98th to the 187 th month. For each of the 19 levels, we recruited a sample of 20 children ( 10 boys and 10 girls) from various schools and day-care centers of Oviedo and gave them the cards for the pictures that they were to name. When they did not know the name of a picture, the card was moved to the bottom of the stack, and they continued. A word was considered to be acquired at 1 of the 19 levels when $75 \%$ of the children of that age and older named it correctly.

\section{Method}

Participants. Thirty psychology students from the same pool as those in Experiment 1 participated in this experiment. All were native speakers of Spanish with normal or corrected-to-normal vision. None of them had participated in Experiment 1.

Stimuli. Of the 345 pictures on the cards, a total of 60 pictures of objects were selected, 15 for each of the following experimental conditions: early AoA-high frequency, early AoA-low frequency, late AoA-high frequency, and late AoA-low frequency. The items in these four categories were similar in familiarity, imageability, visual complexity, and name length. All of the stimuli had name agreement above $85 \%$. The means for the statistical characteristics of the items are shown in Table 5, and the list of items used is provided in Appendix C.

Procedure. The procedure was the same as that used in Experiment 1 .

\section{Results}

As in Experiment 1, prior to the analysis the participants' errors (4.61\%), voice key failures $(4.89 \%)$, and scores more than 2.5 SDs from the mean $(2.67 \%)$ were eliminated. The mean naming latencies, their SDs, and percentages of errors are shown in Table 6.

AoA was significant for both participants $\left[F_{1}(1,29)=\right.$ $107.40]$ and items $\left[F_{2}(1,56)=25.51\right]$. Word frequency was significant neither for participants $\left(F_{1}<1\right)$ nor for stimuli $\left(F_{2}<1\right)$. The interaction between the two factors was significant in the participants analysis $\left[F_{1}(1,29)=\right.$ 9.39] but not in the items analysis $\left[F_{2}(1,56)=2.29\right]$. A larger word frequency effect was found on words acquired early $(-33 \mathrm{msec})$ than on those acquired late $(+8 \mathrm{msec})$.

\section{Discussion}

A different measure of AoA was used, but the results were generally similar to those of the first two experiments. AoA was again highly significant, but word frequency was not. This interaction between AoA and word frequency was reliable only in the participants analysis and, as in Experiment 2, was in the direction opposite that predicted by the Ellis and Lambon Ralph (2000) model. Contrary to Experiment 2, on items acquired early, the frequency effect

Table 4

Mean Naming Times (RTs, in Milliseconds), Standard Deviations, and Percentages of Errors As a Function of AoA and Word Frequency in Experiment 2

\begin{tabular}{|c|c|c|c|}
\hline Word & RT & $S D$ & $\%$ Error \\
\hline \multicolumn{4}{|l|}{ Early acquired } \\
\hline High frequency & 884 & 127 & 6 \\
\hline Low frequency & 816 & 86 & 4 \\
\hline \multicolumn{4}{|l|}{ Late acquired } \\
\hline High frequency & 907 & 98 & 6 \\
\hline Low frequency & 924 & 123 & 13 \\
\hline
\end{tabular}


Table 5

Statistical Characteristics of the Items Used in Experiment 3

\begin{tabular}{lrrrrr}
\hline & \multicolumn{2}{c}{ Early Acquired } & & \multicolumn{2}{c}{ Late Acquired } \\
\cline { 2 - 3 } \cline { 5 - 6 } \multicolumn{1}{c}{ Characteristic } & \multicolumn{1}{c}{ HF } & \multicolumn{1}{c}{ LF } & & \multicolumn{1}{c}{ HF } & \multicolumn{1}{c}{ LF } \\
\hline AoA (objective, in months) & 38.53 & 39.40 & & 126.47 & 128.80 \\
Frequency (per million) & 45.27 & 3.92 & & 48.72 & 3.04 \\
Visual complexity & 2.15 & 2.61 & & 2.46 & 2.71 \\
Imageability & 6.26 & 6.28 & & 6.34 & 6.09 \\
Familiarity & 6.09 & 6.01 & & 6.05 & 5.54 \\
No. of syllables & 2.40 & 2.73 & & 2.47 & 2.60 \\
No. of phonemes & 5.13 & 6.27 & & 5.20 & 5.27 \\
\hline
\end{tabular}

Note-HF, high frequency; LF, low frequency. Visual complexity was rated on a scale of $1-5$, and imageability and familiarity on scales of $1-7$.

was not reversed, since word frequency was larger for items acquired early than for items acquired late.

\section{EXPERIMENT 4}

In this experiment, an orthogonal factorial design was again used, but cumulative frequency was employed as a measure of word frequency. By adding the frequency with which the words appear in childhood to the frequency with which they appear in adulthood, we can get a more reliable estimate of how often a word is encountered over the life span (Zevin \& Seidenberg, 2002). Adult frequency was taken from the LEXESP database (Sebastián et al., 2000), and child frequency was taken from the database of Martínez and García (2004). These authors obtained the values of frequency from a sample of children's books. This sample included reading books as well as textbooks from Grades 1-6 (6-12 years of age). In this database, word frequency at each level, as well as cumulative frequency by levels, is available. For our experiment, we used the sum of the frequencies from all six levels. Since the total number of words of the database is $2,600,000$, we divided the value of each word by 2.6 in order to obtain child frequency per million. Cumulative frequency was computed as the sum of adult frequency per million and child frequency per million. As a measure of AoA, we used AoA ratings as described in Experiment 1.

\section{Method}

Participants. The participants were 32 psychology students at the University of Oviedo who received course credit for their participation. All were native speakers of Spanish and had normal or corrected-to-normal vision. None of them had participated in any of the previous experiments.

Stimuli. Sixty pictures of objects were selected from the same database used in Experiment 1, 15 for each of the following experimental conditions: early AoA-high cumulative frequency, early AoA-low cumulative frequency, late AoA-high cumulative frequency, and late AoA-low cumulative frequency. The items in these four conditions were similar in visual complexity, imageability, familiarity, and length (there were no statistical differences among the four experimental conditions with respect to these variables). All of the pictures had name agreement above $85 \%$. Regarding the initial phonemes, the four experimental conditions included eight words whose first phoneme is voiceless and seven whose first phoneme is voiced. The means for the statistical characteristics for each of the four experimental conditions are shown in Table 7, and the list of items is provided in Appendix D.

Procedure. The procedure was the same as that used in the previous Spanish experiments.

\section{Results and Discussion}

Naming times were excluded from the analyses whenever any of the following conditions held: response error $(1.72 \%)$, technical error of the voice key $(0.16 \%)$, and response times exceeding $2.5 \mathrm{SDs}$ of the mean $(1.77 \%)$. Overall, 3.65 of the observations were discarded. In Table 8, the mean naming latencies, their $S D$ s, and percentages of errors are shown.

As in the previous experiments, items acquired early were named faster than items acquired late $\left[F_{1}(1,31)=\right.$ 49.47 and $\left.F_{2}(1,56)=9.35\right]$. Cumulative frequency was marginally significant for participants $\left[F_{1}(1,31)=3.99\right]$ and not significant for items $\left[F_{2}(1,59)=1.15\right]$. The interaction between AoA and cumulative frequency was significant for participants $\left[F_{1}(1,31)=9.52\right]$ but not for items $\left[F_{2}(1,56)=1.12\right]$. On participants, the interaction indicated that the word frequency effect was larger on items acquired early $(-32 \mathrm{msec})$ than on those acquired late $(+1 \mathrm{msec})$.

Again, the pattern of results is similar to that obtained in the two previous experiments - that is, there was a significant effect of AoA but no reliable effect of frequency, and a weak interaction between the two variables (significant only for participants). Also as in Experiments 2 and 3 , the interaction was opposite that predicted by the Ellis and Lambon Ralph (2000) model.

\section{EXPERIMENT 5}

The four factorial experiments reported thus far do not provide evidence that word frequency and AoA interact, with the result that a larger frequency effect is observed on items acquired late than on items acquired early. In effect, the interaction was reliable only in the participants analyses in Experiments 2, 3, and 4. In none of the experiments was the interaction in the direction predicted by Ellis and Lambon Ralph's (2000) model. It may be the case that the drastic selection conditions imposed by the factorial manipulation of AoA and word frequency lead to the selection of very specific items, which, in turn, leads to some unstable findings. To circumvent this potential problem, in Experiment 5 we opted for a regression approach with

Table 6

Mean Naming Times (RTs, in Milliseconds), Standard Deviations, and Percentages of Errors As a Function of AoA and Word Frequency in Experiment 3

\begin{tabular}{cccc}
\hline Word & RT & $S D$ & \%Error \\
\hline Early acquired & & & \\
High frequency & 638 & 65 & 0.17 \\
Low frequency & 671 & 65 & 0.33 \\
Late acquired & & & \\
High frequency & 790 & 77 & 2.78 \\
Low frequency & 782 & 69 & 1.33 \\
\hline
\end{tabular}


Table 7

Statistical Characteristics of the Items Used in Experiment 4

\begin{tabular}{|c|c|c|c|c|}
\hline \multirow[b]{2}{*}{ Characteristic } & \multicolumn{2}{|c|}{$\begin{array}{c}\text { Early } \\
\text { Acquired }\end{array}$} & \multicolumn{2}{|c|}{ Late Acquired } \\
\hline & $\mathrm{HF}$ & LF & $\mathrm{HF}$ & LF \\
\hline AoA (rated) & 1.87 & 1.88 & 3.01 & 3.03 \\
\hline Frequency (cumulative, per million) & 65.85 & 14.74 & 63.33 & 13.05 \\
\hline Frequency (adult, per million) & 18.63 & 6.76 & 34.37 & 6.15 \\
\hline Visual complexity & 2.58 & 2.36 & 2.59 & 3.06 \\
\hline Imageability & 6.08 & 6.27 & 6.00 & 6.16 \\
\hline Familiarity & 6.15 & 5.96 & 5.91 & 5.86 \\
\hline No. of syllables & 2.47 & 2.67 & 2.60 & 2.60 \\
\hline No. of phonemes & 5.47 & 5.73 & 5.80 & 5.80 \\
\hline
\end{tabular}

Note-HF, high cumulative frequency; LF, low cumulative frequency. Visual complexity was rated on a scale of $1-5$, and imageability and familiarity on scales of $1-7$.

the use of a large set of items. Likewise, we sought the reliability of a word frequency $\times$ AoA interaction with the use of different measures of word frequency and AoA in different analyses.

\section{Method}

Participants. Thirty students at the school of psychology of the University of Oviedo participated in this experiment. All were native Spanish speakers and all had normal or corrected-to-normal vision.

Stimuli. The stimuli were 180 black-and-white drawings selected from the databases referenced in Experiment 1. For all of them, values of AoA, adult frequency, child frequency, cumulative frequency, familiarity, and name agreement were available and taken from the sources previously described. All of the pictures had name agreement higher than $85 \%$.

Procedure. The experiment was carried out in a soundproof room, and the stimuli were presented on a computer screen. The participants entered the room 1 at a time. A microphone was put near the participant's mouth, and he or she had to name the stimuli. Reaction time was recorded by a voice key. Each trial had the following structure: An asterisk was presented for $1,000 \mathrm{msec}$, followed by a picture, which remained on the screen until the participant initiated a response or 3,000 msec had elapsed. The next trial began $1,000 \mathrm{msec}$ after the participant had initiated the response. The pictures were divided into three blocks of 60 , and at the end of each block the participant was allowed to take a break. The presentation of the blocks was balanced, and the stimuli in each block were randomized for each participant. An experimenter was in the room with the participant during the experiment to note errors.

\section{Results and Discussion}

One of the stimuli (aceituna) was eliminated because of a high number of errors. A total of $8.0 \%$ of the response times were eliminated, with $4.9 \%$ corresponding to participant errors, $1.1 \%$ to problems with the voice key, and $2.0 \%$ because they were more than $3 S D$ s above or below the mean.

Two types of regression analysis were done. The first type of analysis was conducted to examine whether or not frequency trajectory was a reliable determinant of the two AoA measures (rated and objective). This has to be established in order to validate the use of frequency trajectory as an operationalization of the age/order of acquisition of words. Therefore, one of the two measures of AoA was used as the dependent variable, and the independent variables were name agreement, conceptual familiarity, imageability, phonological length, frequency trajectory, and cumulative frequency. In the second type of analysis, naming times were considered as the dependent variable whereas the independent variables were name agreement, conceptual familiarity, imageability, phonological length, one measure of AoA (subjective, objective, or frequency trajectory), one measure of frequency (adult frequency or cumulative frequency), and the interaction term corresponding to AoA and word frequency.

Three items (flauta, hada, and pirata) appeared as important outliers in all of the analyses. Therefore, these items were discarded in all the regression analyses reported below.

As is shown in Table 9, frequency trajectory and cumulative frequency were significant determinants of the two AoA measures. Moreover, conceptual familiarity and number of phonemes were also reliable determinants of AoA ratings, as was name agreement for the objective AoA scores.

As far as naming times are concerned (see Table 9), the measures used for AoA were always significant, whereas word frequency was reliable only in the regression equation taking into account cumulative frequency and frequency trajectory. The interaction effect was significant only in the analyses for which the objective AoA measures were used. The positive sign of the beta coefficient of this interaction indicates that a larger frequency effect was found on items acquired early than on items acquired late. It is worth noting that name agreement was always significant, whereas number of phonemes and conceptual familiarity were reliable in the analyses using the objective measures of AoA. Conceptual familiarity was also significant in the regression equation, for which cumulative frequency and frequency trajectory were used.

The findings obtained with the multiple regression approach are consistent with those obtained with the factorial approach (Experiments 3 and 4). Critically, the interaction between AoA and word frequency was reliable only when objective AoA norms were used, and it was in the direction opposite that predicted by the Ellis and Lambon Ralph (2000) model: A larger effect of frequency was observed on items acquired early than on those acquired late.

\section{GENERAL DISCUSSION}

The present study was undertaken to test the reliability of the interaction between AoA and word frequency in picture naming latencies in normal participants. This

Table 8

Mean Naming Times (RTs, in Milliseconds), Their Standard Deviations, and Percentages of Errors As a Function of AoA and Word Frequency in Experiment 4

\begin{tabular}{cccc}
\hline Word & RT & $S D$ & \%Error \\
\hline Early acquired & & & \\
High frequency & 773 & 73 & 0.36 \\
Low frequency & 805 & 83 & 0.42 \\
Late acquired & & & \\
High frequency & 839 & 77 & 0.31 \\
Low frequency & 838 & 87 & 0.63 \\
\hline
\end{tabular}


Table 9

Summary of the Regression Analyses in Experiment 5

\begin{tabular}{llllcll}
\hline \multicolumn{1}{c}{ DV } & AoA/Freq & $\beta$ AoA & $\beta$ Freq & $\beta($ AoA $\times$ Freq $)$ & $R^{2}$ & Other \\
\hline Rated AoA & FT/CF & $.294^{* *}$ & $-.383^{\dagger}$ & & .420 & Fam, Phon \\
Ojective AoA & FT/CF & $.264^{* *}$ & $-.287^{\dagger}$ & & .305 & NA \\
Naming latencies & rated/adult & $.220^{*}$ & -.079 & .067 & .266 & NA \\
& rated/CF & $.175^{*}$ & -.142 & .032 & .271 & NA \\
& objective/adult & $.561^{* *}$ & -.032 & $.135^{*}$ & .483 & NA, Fam, Phon \\
& objective/CF & $.562^{* *}$ & -.042 & $.142^{*}$ & .484 & NA, Fam, Phon \\
& FT/CF & $.152^{*}$ & $-.230^{* *}$ & .051 & .273 & NA, Fam \\
\hline
\end{tabular}

Note-DV, dependent variable; Freq, frequency per million words; $\beta$, beta coefficient; $R^{2}, R^{2}$ for the entire set of independent variables; Other, other significant predictors; Fam, familiarity; Phon, number of phonemes; NA, name agreement; FT, frequency trajectory; CF, cumulative frequency. ${ }^{*} p<.05 .{ }^{* *} p<.01 .{ }^{\dagger} p<$ .001 .

interaction has not yet been investigated in a systematic manner, and the few studies in which it was tested have yielded inconsistent findings (e.g., Lambon Ralph \& Ehsan, 2006; Meschyan \& Hernandez, 2002). Because this interaction is clearly predicted by certain views of AoA in lexical processing (Ellis \& Lambon Ralph, 2000; Lambon Ralph \& Ehsan, 2006), we aimed to determine whether it would be found reliably in picture naming latencies. In particular, the finding of a reliably larger influence of word frequency for words acquired late than for those acquired early in naming speed would provide additional support for the connectionist approach of AoA in lexical processing advocated by Ellis and Lambon Ralph (see also Monaghan \& Ellis, 2002b).

A series of five experiments was conducted to test the interaction between word frequency and AoA in picture naming latencies using both a factorial (four experiments) and a multiple regression (one experiment) approach. The interaction was reliable in three of the four factorial experiments, but only in the participants analyses. Moreover, the direction of the interaction was different from that predicted in Experiments 2, 3, and 4. In Experiment 5, in which a regression approach was used, the interaction was tested in several analyses using different measures of AoA and word frequency. Only when objective AoA norms were included in the analyses was the interaction significant. However, a close examination of the interaction indicated that it was not in the direction predicted by the Ellis and Lambon Ralph (2000) model, since a larger frequency effect was found on items acquired early than on those acquired late.

It might be asked why we used both a factorial and a regression approach to investigate this issue and not only a factorial approach, since the latter is sometimes thought to be the more appropriate approach (but see Méot \& Bonin, in press) in the sense that it allows more reliable conclusions than the former approach. The factorial approach imposes drastic selection conditions when the factors of interest are highly related, as is the case for word frequency and AoA. Very specific items may be selected, and the results obtained under these conditions are sometimes difficult to generalize. Indeed, in our experiments the results were mostly significant in the participants analyses and not in the items analyses. Moreover, the interaction had a different form in one of two experiments in which the interaction was reliable for participants. The multiple regression approach allows more generalization but suffers from less internal validity than the factorial approach (Méot \& Bonin, in press). Importantly, the pattern of findings concerning the interaction between word frequency and AoA in picture naming latencies was highly similar between the two approaches.

As we explained in the introduction, one of the most influential views of AoA effects in lexical processing is that of Ellis and Lambon Ralph (2000). According to this view, AoA effects are the result of a loss of plasticity in learning of the network. Patterns acquired late can be learned, but they have fewer degrees of freedom to change the weights relating to different codes to represent themselves. This view also predicts an influence of the frequency of encounter of the patterns during the learning of the network. Importantly, the two factors - order of introduction and frequency of word encounter-combine, with the result that a larger frequency effect is found on patterns introduced late in the learning of the network than on those introduced earlier. Barry et al. (1997) reported a reliable interaction between word frequency and AoA in a multiple regression study. The form of the interaction was in the direction predicted by Ellis and Lambon Ralph - that is, word frequency had a larger influence on picture items acquired late than on those acquired early. Barry et al. (1997) accounted for this interaction by assuming that word frequency is encoded in the links relating semantic and phonological representations, whereas AoA is located in the lexical representations themselves. However, the hypothesis that AoA is located at the level of phonological representations has been challenged by Monaghan and Ellis (2002a). Furthermore, it should be remembered that the interaction found by Barry et al. (1997) is not very robust because it was not reliable when objective AoA measures were used. Even in the recent study of Lambon Ralph and Ehsan (2006), the interaction between AoA and word frequency in naming latencies was not reliable on items.

The connectionist view of AoA and word frequency advocated by Zevin and Seidenberg (2002) is compatible with the model of Ellis and Lambon Ralph (2000) in 
that it also predicts an influence of cumulative word frequency in all lexical processing tasks. However, according to Zevin and Seidenberg (2004), reliable age-limited effects are anticipated only in tasks that mobilize arbitrary mappings, such as picture and face naming. This view has been supported by both behavioral (Bonin et al., 2004) and computational (Lambon Ralph \& Ehsan, 2006; Zevin \& Seidenberg, 2002) data. Zevin and Seidenberg (2002) did not provide computational evidence for an interaction between the two factors when the mappings between codes are arbitrary. However, Lambon Ralph and Ehsan provided computational evidence for such an interaction when the mappings between input and output codes are arbitrary. The implications of our findings are clear: Although a word frequency $\times$ AoA interaction can be found in certain studies, it is certainly not robust. Moreover, the direction of the interaction varies across studies. Therefore, spoken production models that predict an interaction between word frequency and AoA will have to be altered so as to account for the fact that this interaction is not stable and often unreliable in behavioral data. It is worth mentioning here that Stadthagen-Gonzalez, Bowers, and Damian (2004) found, in a lexical decision task, which requires semantic access under certain conditions (Plaut, 1997), that even though some words become very frequent in certain populations (e.g., carbon for chemists, behavior for psychologists), they never gain a processing advantage over some early acquired words whose frequency declines in adulthood (e.g., dragon).

Across our series of experiments, we found that AoA was a reliable determinant of naming speed regardless of which measure was used: subjective ratings, objective scores derived from child performance, or frequency trajectory. However, word frequency was found to be reliable only when cumulative frequency was used in the regression analysis in Experiment 5. These findings accord with those obtained in other studies. In fact, significant effects of AoA and no reliable effects of word frequency have been reported in regression (Bonin et al., 2002; Carroll \& White, 1973; Chalard et al., 2003; Gilhooly \& Gilhooly, 1979; Morrison et al., 1992; Vitkovitch \& Tyrell, 1995) and semifactorial (Barry et al., 2001; Bonin et al., 2001) studies. The observation that word frequency was reliable when cumulative frequency was used in Experiment 5 is consistent with the claim made by Zevin and Seidenberg (2002) that word frequency norms should take into account child frequencies and not only adult frequency if one aims to have a better estimation of the frequency of encounter of words over the life span. However, the use of cumulative frequency does not always result in the emergence of a reliable effect of frequency, since it was not significant in Experiment 4.

To conclude, our study makes a strong contribution in showing that the modulation of word frequency as a function of the AoAs of words is not a robust finding in the picture naming performance of adults. The interaction that is clearly predicted by one influential connectionist view of AoA effects in lexical processing (Ellis \& Lambon Ralph, 2000) is therefore constrained by these data.

\section{REFERENCES}

Alario, F.-X., \& Ferrand, L. (1999). A set of 400 pictures standardized for French: Norms for name agreement, image agreement, familiarity, visual complexity, image variability, and age of acquisition. Behavior Research Methods, Instruments, \& Computers, 31, 531-552.

alario, F.-X., Ferrand, L., Laganaro, M., New, B., Frauenfelder, U. H., \& SEgUI, J. (2004). Predictors of picture naming speed. Behavior Research Methods, Instruments, \& Computers, 36, 140-155.

Barry, C., Hirsh, K., Johnston, R. A., \& Williams, C. L. (2001). Age of acquisition, word frequency and the locus of repetition priming of picture naming. Journal of Memory \& Language, 44, 350-375.

Barry, C., Morrison, C. M., \& Ellis, A. W. (1997). Naming the Snodgrass and Vanderwart pictures: Effects of age of acquisition, frequency and name agreement. Quarterly Journal of Experimental Psychology, 50A, 560-585.

BERINGER, J. (1995). Experimental Run Time System [Software]. Frankfurt: BeriSoft.

Bonin, P., Barry, C., MÉot, A., \& Chalard, M. (2004). The influence of age of acquisition in word reading and other tasks: A never ending story? Journal of Memory \& Language, 50, 456-476.

Bonin, P., Chalard, M., Méot, A., \& Fayol, M. (2002). The determinants of spoken and written picture naming latencies. British Journal of Psychology, 93, 89-114.

Bonin, P., Fayol, M., \& Chalard, M. (2001). Age of acquisition and word frequency in written picture naming. Quarterly Journal of Experimental Psychology, 54, 469-489.

Bonin, P., Peereman, R., Malardier, N., Méot, A., \& Chalard, M. (2003). A new set of 299 pictures for psycholinguistic studies: French norms for name agreement, image agreement, conceptual familiarity, visual complexity, image variability, age of acquisition, and naming latencies. Behavior Research Methods, Instruments, \& Computers, 35, 158-167.

Carroll, J. B., \& White, M. N. (1973). Word frequency and age-ofacquisition as determiners of picture-naming latency. Quarterly Journal of Experimental Psychology, 25, 85-95.

Chalard, M., Bonin, P., Méot, A., Boyer, B., \& Fayol, M. (2003). Objective age-of-acquisition (AoA) norms for a set of 230 object names in French: Relationship with psycholinguistic variables, the English data from Morrison et al. (1997) and naming latencies. European Journal of Cognitive Psychology, 15, 209-245.

Cohen, J., MacWhinney, B., Flatt, M., \& Provost, J. (1993). PsyScope: An interactive graphic system for designing and controlling experiments in the psychology laboratory using Macintosh computers. Behavior Research Methods, Instruments, \& Computers, 25, 257 271.

Content, A., Mousty, P., \& Radeau, M. (1990). Brulex: Une base de donneés informatisées pour le français écrit et parlé [A computerized database for written and spoken French]. L'Année Psychologique, 90, 551-566.

Cuetos, F., Ellis, A. W., \& Alvarez, B. (1999). Naming times for the Snodgrass and Vanderwart pictures in Spanish. Behavior Research Methods, Instruments, \& Computers, 31, 650-658.

Cycowicz, Y. M., Friedman, D., Rothstein, M., \& Snodgrass, J. G. (1997). Picture naming by young children: Norms for name agreement, familiarity and visual complexity. Journal of Experimental Child Psychology, 65, 171-237.

DeLl, G. S. (1990). Effects of frequency and vocabulary type on phonological speech errors. Language \& Cognitive Processes, 5, 313-349.

Dunn, L. M., \& Dunn, L. M. (1986). Test de vocabulario en imágenes Peabody. Madrid: MEPSA.

Ellis, A. W., \& Lambon Ralph, M. A. (2000). Age of acquisition effects in adult lexical processing reflect loss of plasticity in maturing systems: Insights from connectionist networks. Journal of Experimental Psychology: Learning, Memory, \& Cognition, 26, 1103-1123.

Ellis, A. W., \& Morrison, C. M. (1998). Real age of acquisition effects 
in lexical retrieval. Journal of Experimental Psychology: Learning, Memory, \& Cognition, 24, 515-523.

Gilhooly, K. J., \& Gilhooly, M. L. [M.] (1979). Age-of-acquisition effects in lexical and episodic memory tasks. Memory \& Cognition, 7, 214-223.

Gilhooly, K. J., \& Gilhooly, M. L. M. (1980). The validity of age-ofacquisition ratings. British Journal of Psychology, 71, 105-110.

Gilhooly, K. J., \& Logie, R. H. (1980). Age-of-acquisition, imagery, concreteness, familiarity, and ambiguity measures for 1,944 words. Behavior Research Methods \& Instrumentation, 12, 395-427.

Humphreys, G. W., Riddoch, M. J., \& Quinlan, P. T. (1988). Cascade processes in picture identification. Cognitive Neuropsychology, 5, 67-103.

Huttenlocher, J., \& KubiceK, L. E. (1983). The sources of relatedness effects on naming latency. Journal of Experimental Psychology: Learning, Memory, \& Cognition, 9, 486-496.

Jescheniak, J. D., \& Levelt, W. J. M. (1994). Word frequency effects in speech production: Retrieval of syntactic information and of phonological form. Journal of Experimental Psychology: Learning, Memory, \& Cognition, 20, 824-843.

Johnston, R. A., \& BARRY, C. (in press). Age-of-acquisition effects in the semantic processing of pictures. Memory \& Cognition.

Lachman, R., Shaffer, J. P., \& HennRikus, D. (1974). Language and cognition: Effects of stimulus codability, name-word frequency and age-of-acquisition on lexical reaction time. Journal of Verbal Learning \& Verbal Behavior, 13, 775-784.

LAMBOn RalPh, M. A., \& EHSAn, S. (2006). Age of acquisition effects depend on the mapping between representations and the frequency of occurrence: Empirical and computational evidence. Visual Cognition, 13, 928-948.

Levelt, W. J. M., Roelofs, A., \& Meyer, A. S. (1999). A theory of lexical access in speech production. Behavioral \& Brain Sciences, 22, 1-75.

Martínez, J. A., \& García, M. E. (2004). Inventario silábico del lenguaje escrito dirigido a los niños de primaria. Cognitiva, 16, 43-56.

MÉOT, A., \& Bonin, P. (in press). Faut-il préférer l'analyse de variance à l'analyse de régression linéaire multiple pour les expériences utilisant des VI continues? L'Année Psychologique.

Meschyan, G., \& Hernandez, A. (2002). Age of acquisition and word frequency: Determinants of object-naming speed and accuracy. Memory \& Cognition, 30, 262-269.

Monaghan, J., \& Ellis, A. W. (2002a). Age of acquisition and the completeness of phonological representations. Reading \& Writing, 15, 759-788.

Monaghan, J., \& Ellis, A. W. (2002b). What exactly interacts with spelling-sound consistency in word naming? Journal of Experimental Psychology: Learning, Memory, \& Cognition, 28, 183-206.
Morrison, C. M., Chappell, T. D., \& Ellis, A. W. (1997). Age of acquisition norms for a large set of object names and their relation to adult estimates and other variables. Quarterly Journal of Experimental Psychology, 50A, 528-559.

Morrison, C. M., \& ElLis, A. W. (2000). Real age of acquisition effects in word reading and lexical decision. British Journal of Psychology, 91, $167-180$.

Morrison, C. M., Ellis, A. W., \& Quinlan, P. T. (1992). Age of acquisition, not word frequency, affects object naming, not object recognition. Memory \& Cognition, 20, 705-714.

New, B., Pallier, C., Ferrand, L., \& Matos, R. (2001). Une base de données lexicales du français contemporain sur Internet: LEXIQUE. L'Année Psychologique, 101, 447-462.

OldField, R. C., \& Wingfield, A. (1965). Response latencies in naming objects. Quarterly Journal of Experimental Psychology, 17, 273-281.

Pind, J., Jónsdóttir, H., Gissurardóttir, H., \& Jónsson, F. (2000). Icelandic norms for the Snodgrass and Vanderwart (1980) pictures: Name and image agreement, familiarity and age of acquisition. Scandinavian Journal of Psychology, 41, 41-48.

Plaut, D. C. (1997). Structure and function in the lexical system: Insights from distributed models of word reading and lexical decision. Language \& Cognitive Processes, 12, 767-808.

Sebastián, N., Martí, M. A., Carreiras, M., \& Cuetos, F. (2000). LEXESP: Léxico informatizado del español. Barcelona: University of Barcelona Press.

Snodgrass, J. G., \& Vanderwart, M. (1980). A standardized set of 260 pictures: Norms for name agreement, image agreement, familiarity, and visual complexity. Journal of Experimental Psychology: Human Learning \& Memory, 6, 174-215.

SnOdgRass, J. G., \& Yuditsky, T. (1996). Naming times for the Snodgrass and Vanderwart pictures. Behavior Research Methods, Instruments, \& Computers, 28, 516-536.

Stadthagen-Gonzalez, H., Bowers, J. S., \& Damian, M. F. (2004). Age-of-acquisition effects in visual word recognition: Evidence from expert vocabularies. Cognition, 93, B11-B26.

Valle, F., \& Cuetos, F. (1995). EPLA: Evaluación del procesamiento lingüístico en la afasia. Hove, U.K.: Erlbaum.

VitKovitch, M., \& TYrell, L. (1995). Sources of disagreement in object naming. Quarterly Journal of Experimental Psychology, 21A, 1155-1168.

Zevin, J. D., \& Seidenberg, M. S. (2002). Age of acquisition effects in word reading and other tasks. Journal of Memory \& Language, 47, 1-29.

Zevin, J. D., \& Seidenberg, M. S. (2004). Age-of-acquisition effects in reading aloud: Tests of cumulative frequency and frequency trajectory. Memory \& Cognition, 32, 31-38. 
APPENDIX A

List of the Stimuli Used in Experiment 1 With Their Approximate English Translations

\begin{tabular}{|c|c|c|c|c|c|c|c|}
\hline \multicolumn{2}{|c|}{ EA-HF } & \multicolumn{2}{|c|}{ EA-LF } & \multicolumn{2}{|c|}{ LA-HF } & \multicolumn{2}{|r|}{ LA-LF } \\
\hline Stimulus & Translation & Stimulus & Translation & Stimulus & Translation & Stimulus & Translation \\
\hline castillo & castle & gorro & cap & bomba & bomb & candado & padlock \\
\hline oreja & ear & pato & duck & monte & mountain & lupa & magnifying glass \\
\hline perro & $\operatorname{dog}$ & columpio & swing & disco & record & buzo & diver \\
\hline pelota & ball & chupete & pacifier & órgano & organ & arado & plough \\
\hline abrigo & coat & cuchara & spoon & chaleco & vest & cerilla & match \\
\hline árbol & tree & peine & comb & navaja & penknife & tanque & $\operatorname{tank}$ \\
\hline huevo & egg & calcetín & sock & diana & bull's-eye & muletas & crutches \\
\hline tarta & cake & tortuga & turtle & granada & grenade & jabalí & wild boar \\
\hline regalo & present & bota & boot & pesa & weight & antifaz & mask \\
\hline pájaro & bird & hada & fairy & bandera & flag & canguro & kangaroo \\
\hline vaso & glass & hormiga & ant & antena & antenna & teclado & keyboard \\
\hline circo & circus & payaso & clown & fábrica & factory & taladro & drill \\
\hline zapato & shoe & pera & pear & huella & print & arpa & harp \\
\hline dedo & finger & luna & moon & corbata & tie & avestruz & ostrich \\
\hline silla & chair & plátano & banana & arco & bow & salero & saltshaker \\
\hline
\end{tabular}

Note-EA, early acquired; LA, late acquired; HF, high frequency; LF, low frequency.

\section{APPENDIX B}

List of the Stimuli Used in Experiment 2 With Their Approximate English Translations

\begin{tabular}{|c|c|c|c|c|c|c|c|}
\hline \multicolumn{2}{|c|}{$\mathrm{EA}-\mathrm{HF}$} & \multicolumn{2}{|c|}{ EA-LF } & \multicolumn{2}{|c|}{ LA-HF } & \multicolumn{2}{|c|}{ LA-LF } \\
\hline Stimulus & Translation & Stimulus & Translation & Stimulus & Translation & Stimulus & Translation \\
\hline âne & donkey & balai & brush & avocat & avocado & ampoule & bulb \\
\hline botte & boot & balançoire & swing & balance & balance & bocal & bottle \\
\hline chèvre & goat & canapé & sofa & bureau & desk & boussole & compass \\
\hline cloche & bell & cerise & cherry & canon & cannon & cendrier & ashtray \\
\hline cochon & pig & cheveux & hair & cerveau & brain & cerf & deer \\
\hline corde & rope & ciseau & chisel & chaîne & chain & chenille & caterpillar \\
\hline couronne & crown & clown & clown & cigare & cigar & commode & closet \\
\hline couteau & knife & crocodile & crocodile & drapeau & flag & dinosaure & dinosaur \\
\hline loup & wolf & douche & shower & enveloppe & envelope & hamac & hammock \\
\hline lune & moon & éléphant & elephant & fouet & whip & pince & grip \\
\hline manteau & coat & fraise & strawberry & pipe & pipe & pyramide & pyramid \\
\hline mouton & sheep & moto & motorcycle & poignée & handle & requin & shark \\
\hline nuage & cloud & poire & pear & prise & plug & sacoche & sleeping bag \\
\hline poule & hen & roue & wheel & puits & well & ski & ski \\
\hline tasse & cup & stylo & pen & règle & ruler & thermomètre & thermometer \\
\hline vache & cow & tabouret & stool & veste & jacket & visse & screw \\
\hline valise & suitcase & tortue & turtle & violon & violin & voilier & sailing ship \\
\hline
\end{tabular}

Note-EA, early acquired; LA, late acquired; HF, high frequency; LF, low frequency. 
APPENDIX C

List of the Stimuli Used in Experiment 3 With Their Approximate English Translations

\begin{tabular}{|c|c|c|c|c|c|c|c|}
\hline \multicolumn{2}{|c|}{$\mathrm{EA}-\mathrm{HF}$} & \multicolumn{2}{|c|}{ EA-LF } & \multicolumn{2}{|c|}{ LA-HF } & \multicolumn{2}{|c|}{$\mathrm{LA}-\mathrm{LF}$} \\
\hline Stimulus & Translation & Stimulus & Translation & Stimulus & Translation & Stimulus & Translation \\
\hline escalera & stepladder & escoba & broom & labios & lips & acordeón & accordion \\
\hline estrella & star & plátano & banana & camisa & shirt & cazo & saucepan \\
\hline vestido & dress & tenedor & fork & banco & bench & canoa & canoe \\
\hline dedo & finger & pato & duck & abrigo & coat & zorro & fox \\
\hline botella & bottle & cesta & basket & ventana & window & jarra & jar \\
\hline caja & box & uvas & grapes & chaqueta & jacket & rana & frog \\
\hline flor & flower & calcetín & sock & médico & doctor & pimiento & pepper* \\
\hline vaso & glass & tijeras & scissors & muro & wall & hórreo & granary \\
\hline ojo & eye & silbato & whistle & red & net & pomo & handle \\
\hline caballo & horse & columpio & swing & paquete & package & enchufe & plug \\
\hline bandera & flag & peine & comb & bigote & mustache & barca & boat \\
\hline pájaro & bird & mariposa & butterfly & copa & wineglass & cereza & cherry \\
\hline pez & fish & pinza & clothes peg & sofá & sofa & valla & fence \\
\hline luna & moon & regadera & watering can & nube & cloud & hormiga & ant \\
\hline vela & candle & fresa & strawberry & oreja & ear & tornillo & screw \\
\hline
\end{tabular}

Note_EA, early acquired; LA, late acquired; HF, high frequency; LF, low frequency. ${ }^{*}$ I.e., fruit.

\section{APPENDIX D}

List of the Stimuli Used in Experiment 4 With Their Approximate English Translations

\begin{tabular}{|c|c|c|c|c|c|c|c|}
\hline \multicolumn{2}{|c|}{$\mathrm{EA}-\mathrm{HF}$} & \multicolumn{2}{|c|}{ EA-LF } & \multicolumn{2}{|c|}{ LA-HF } & \multicolumn{2}{|c|}{ LA-LF } \\
\hline Stimulus & Translation & Stimulus & Translation & Stimulus & Translation & Stimulus & Translation \\
\hline planta & plant & caramelo & candy & flauta & flute & canguro & kangaroo \\
\hline campana & bell & peonza & top & torre & tower & cangrejo & crab \\
\hline flor & flower & peine & comb & cerebro & brain & cerezas & cherries \\
\hline queso & cheese & pera & pear & cadena & chain & pulpo & octopus \\
\hline pantalón & pants & tobogán & slide & pulmones & lungs & cisne & swan \\
\hline pierna & leg & falda & skirt & planeta & planet & cebolla & onion \\
\hline naranja & orange & payaso & clown & copa & wineglass & piña & pineapple \\
\hline oso & bear & columpio & swing & camisa & shirt & seta & mushroom \\
\hline helado & ice cream & lazo & bow* & $\operatorname{arco}$ & bow $^{\dagger}$ & brújula & compass \\
\hline araña & spider & ducha & shower & mapa & map & bomba & bomb \\
\hline gallina & hen & regadera & watering can & nido & nest & garaje & garage \\
\hline lápiz & pencil & biberón & feeding bottle & ordenador & computer & molino & mill \\
\hline vaso & glass & grifo & tap & linterna & lantern & buzón & postbox \\
\hline elefante & elephant & ola & wave & espada & sword & raqueta & racquet \\
\hline gorro & cap & bañera & bathtub & vela & candle & mechero & lighter \\
\hline
\end{tabular}

Note-EA, early acquired; LA, late acquired; HF, high frequency; LF, low frequency. *Decorative bow. †Bow for archery.

(Manuscript received January 20, 2004;

revision accepted for publication June 27, 2005.) 